\title{
How do we spell maze? A dialogue concerning definitions and goals
}

Niv Ad, MD

\section{See related article on page 1433.}

Supplemental material is available online.
From the Inova Heart and Vascular Institute, Falls Church, Va.

Received for publication July 7, 2006; accepted for publication Aug 30, 2006.

Address for reprints: Niv Ad, MD, Director of Cardiac Surgery Research, Inova Heart and Vascular Institute, 3300 Gallows Rd, Falls Church, VA 22042 (E-mail: niv.ad@ inova.com).

J Thorac Cardiovasc Surg 2006;132:1253-5

0022-5223/\$32.00

Copyright (C) 2006 by The American Association for Thoracic Surgery

doi:10.1016/j.jtcvs.2006.08.046
I $\mathrm{n}$ this issue of the Journal, Ballaux and colleagues ${ }^{1}$ from The Netherlands present their experience with more than 200 patients who underwent the cut-and-sew maze III procedure. The study was designed to assess the long-term results of the maze III procedure.

In recent years we have witnessed a significant increase in the number of surgical procedures performed to ablate atrial fibrillation. As a result, there is a flux of publications reporting the results of such procedures. However, most of the studies do not address the true impact of the procedure on patients' outcome and well-being. The literature is also lacking information regarding the correlation between the success in ablating atrial fibrillation and a favorable long-term outcome.

The authors of this article are to be congratulated for their excellent results in a large series of patients. Nevertheless, the current report brings to attention the difficulties and challenges that we currently experience when assessing the results of surgical treatment for atrial fibrillation and its impact on patient outcomes.

Although atrial fibrillation is considered by many to be an innocuous arrhythmia, it may be associated with significant mortality and morbidity. The main focus is obviously the risk of thromboembolic events and strokes; however, heart failure may develop in a significant number of patients. There is also growing evidence that atrial fibrillation can cause patients discomfort and anxiety with a negative impact on quality of life. ${ }^{2}$ Therefore, the nonpharmacologic treatment to be offered to patients at risk for a complicated course is reasonable. ${ }^{3}$

\section{Definition of the Surgical Treatment for Atrial Fibrillation}

The first maze procedure was performed on September 25, 1987, only after extensive laboratory work. The maze I procedure, ${ }^{4}$ the original surgical technique for the treatment of atrial fibrillation, was modified to become the maze II procedure and later the maze III procedure because of late chronotropic problems with the sinoatrial node and intra-atrial conduction. The lesions of the maze procedure are well defined, and except for the septal incision, all of them were found to be important in achieving success in restoring sinus rhythm. Although successful, the maze procedure never gained popularity among cardiac surgeons and cardiologists mainly because of its complexity.

In 1998, Haissaguerre and colleagues ${ }^{5}$ published a key article in the New England Journal of Medicine showing that the pulmonary veins are the source of the ectopic beats leading to atrial fibrillation in most patients with paroxysmal atrial fibrillation. These findings, combined with the relative complexity of the original maze procedure and a number of new surgical ablation devices, led to a flux of new surgical procedures, most of which, if not all, were referred to as the "modified maze procedure." 6 
The combination of the new surgical procedures and ablative devices using different energy sources led to a state of confusion, because in almost every report a different type of ablation device was used to apply a different lesion set.

The maze procedure should be executed exactly as was described by Dr James L. Cox. If the procedure is not performed according to this description, then it should not be referred to as the "maze procedure." More so, the term "maze" should not be included to describe any of the modifications to the maze procedure to avoid confusion. For example, pulmonary vein isolation should not be labeled as the "modified maze procedure" or "mini-maze."

In this issue the authors describe the surgical procedure as the "unmodified maze procedure," yet it is clearly stated by the authors that a possible explanation for their results being inferior to those demonstrated by the group from Washington University in St Louis may be because in their series they applied the cryolesion over the coronary sinus, not as originally described. ${ }^{4}$ The coronary sinus lesion is important, and a failure to apply it the way it was designed may result in a higher failure rate than expected. This is a good example of why we should all be careful when assessing the success of the maze procedure. We should be aware of the differences between the maze procedure as described by Dr Cox and other surgical ablation procedures that are being published.

Nevertheless, the authors' statement regarding the need for better understanding the differences between the various procedures and the surgical modifications is important, and prospective randomized studies should be a unified goal.

\section{Goals of the Surgical Treatment for Atrial Fibrillation}

When assessing the success of the surgical treatment for atrial fibrillation, the following variables are important:

1. Success in restoring sinus rhythm

2. Reduced risk of thromboembolic events

3. Improved quality of life

The definitions of success and failure of the surgical treatment for atrial fibrillation are important. In general, we have yet to establish a set of follow-up guidelines to deal with the definition of success and failure (eg, valve surgery and coronary artery bypass graft surgery). Currently most of the reports rely on patients' perceptions regarding their rhythm and/or a single electrocardiogram strip. We all know that this is likely not sufficient, yet this is the reality of current practice. To change the current practice, specific guidelines of follow-up and definitions of success and failure need to be established and published.

In this study the authors place a considerable amount of emphasis on acquiring more data from the patients. As a result, we have much more information regarding the incidence of postoperative arrhythmia. Nevertheless, there is a significant difference in the method of follow-up for pa- tients who were followed by the surgeons or referring physicians.

An important question that we have yet to answer is whether short bursts of atrial arrhythmia are clinically significant and should be defined as a failure of the procedure. The answer should be associated to the incidence of thromboembolic events and improved quality of life. This study and others show that the maze procedure is effective in reducing the risk of strokes. ${ }^{7}$ The success in reducing the risk of strokes in the surgical population is important and thus should be considered as one of the components of a successful procedure. Unlike most of the patients undergoing catheter ablation, the majority of patients who underwent surgery in this series and in others had at least one major risk factor for stroke when in atrial fibrillation.

Data regarding the improvement in quality of life are lacking. We need more prospective studies designed to correlate the success in ablating atrial fibrillation and quality of life. One of the components of success of the surgical procedure is to improve quality of life. This can be accomplished even in patients who are in some sort of atrial arrhythmia after an intervention and yet have improved quality of life. Therefore it is important to establish a more comprehensive arrhythmia and quality of life follow-up protocol to be able to prospectively link the success in ablating atrial fibrillation and improvements in patients' outcome. Our recent protocol includes a longitudinal quality of life assessment, using validated tools, of all patients undergoing surgery for atrial fibrillation.

\section{Conclusion}

The surgical community should be specific when defining the surgical procedure used to ablate atrial fibrillation. Most of the medical community is not familiar with the fine details about the maze procedure and its modifications. Therefore, avoiding the terms "modified maze" and "minimaze" when describing a procedure is appropriate. The term "maze procedure" should only be used to describe the procedure as it was designed by Dr James L. Cox. ${ }^{4}$

There is a need to establish a standard of care for patients after surgery for atrial fibrillation. Clear follow-up guidelines should be published and followed. A better follow-up with increased awareness of patients' arrhythmias and associated symptoms will result in adequate treatment and improvement in the long-term success of the procedure. ${ }^{7}$

In general, the patients who present for surgical ablation of atrial fibrillation pose a challenge, because the arrhythmia is usually accompanied with an enlarged left atrium and advanced tissue remodeling. Thus, by using a limited lesion set in these patients, a less favorable success rate should be expected.

The appendix includes additional relevant references. 


\section{References}

1. Ballaux P, Guillaume SC, Geuzebroek MS, van Hemel NM, Kelder JC, Dossche K, et al. Freedom of atrial arrhythmias after classical maze III surgery, a 10-year experience. J Thorac Cardiovasc Surg. 2006;132: 1433-40.

2. Practice parameter, stroke prevention in patients with nonvalvular atrial fibrillation. Report of the quality standards subcommittee of the American Academy of Neurology. Neurology. 1998;51:671-3.

3. Cox JL, Ad N, Palazzo T. Impact of the maze procedure on the stroke rate in patients with atrial fibrillation. J Thorac Cardiovasc Surg. 1999;118:833-40.
4. Cox JL. The surgical treatment of atrial fibrillation: IV, Surgical technique. J Thorac Cardiovasc Surg. 1991;101:584-92.

5. Haissaguerre M, Jais P, Shah DC, Takahashi A, Hocini M, Quiniou $\mathrm{G}$, et al. Spontaneous initiation of atrial fibrillation by ectopic beats originating in the pulmonary veins. N Engl J Med. 1998;339:65966.

6. Gariddo MJ, Williams M, Argenziano M. Minimally invasive surgery for atrial fibrillation: toward a totally endoscopic, beating heart approach. J Card Surg. 2004;19:216-20.

7. Barnett SD, Ad N. Surgical ablation as treatment for the elimination of atrial fibrillation: a meta-analysis. J Thorac Cardiovasc Surg. 2006;131: 1029-35.

\section{U THE MOVE?}

Don't miss a single issue of the journal! To ensure prompt service when you change your address, please photocopy and complete the form below.

Please send your change of address notification at least six weeks before your move to ensure continued service. We regret we cannot guarantee replacement of issues missed due to late notification.

\section{JOURNAL TITLE:}

Fill in the title of the journal here.

\section{OLD ADDRESS:}

Affix the address label from a recent issue of the journal here.

\section{NEW ADDRESS:}

Clearly print your new address here.

Name

Address

City/State/ZIP

\section{COPY AND MAIL THIS FORM TO:}

Elsevier Inc.

Subscription Customer Service

6277 Sea Harbor Dr

Orlando, FL 32887
OR FAX TO:

407-363-9661

OR E-mail:

elspcs@elsevier.com
OR PHONE:

800-654-2452

Outside the U.S., call

407-345-4000 


\section{E Appendix \\ Selected Literature}

Ad N, Barnett SD, Lefrak EA, Korach A, Pollak A, Gilon A, et al. The impact of follow-up on the success rate of the cryosurgical maze procedure in patients with rheumatic heart disease and enlarged atria. J Thorac Cardiovasc Surg. 2006;131:1073-9.

Anne W, Willems R, Adriaenssens B, Adams J, Ector H, Heidbuchel H. Long-term symptomatic benefit after radiofrequency catheter ablation for atrial flutter despite a high incidence of post procedural atrial fibrillation. Acta Cardiol. 2006; 61:75-82.

Bando K, Kobayashi J, Sasako Y, Tagusari O, Niwaya K, Kitamura S. Effect of maze procedure in patients with atrial fibrillation undergoing valve replacement. J Heart Valve Dis. 2002;11:719-24.

Benjamin EJ, Wolf PA, D’Agostino BD, Silbershatz H, Kannel WB, Levy D. Impact of atrial fibrillation on the risk of death: The Framingham Study. Circulation. 1998;98:946-52.

Benussi S, Nascimbene S, Agricola E, Calori G, Calvi S, Caldarola A, et al. Surgical ablation of atrial fibrillation using the epicardial radiofrequency approach: mid-term results and risk analysis. Ann Thorac Surg. 2002;74:1050-6; discussion 1057.

Chen MS, Marrouche NF, Khaykin Y, Gillinov AM, Wazni O, Saliba W, et al. Pulmonary vein isolation for the treatment of atrial fibrillation in patients with impaired systolic function. $J$ Am Coll Cardiol. 2004;43:1004-9.
Cox JL, Ad N, Palazzo T. The importance of coronary sinus cryoablation in the maze procedure. Semin Thorac Cardiovasc Surg. 2000;12:20-4.

Kabbani SS, Murad G, Jamil H, Sabbagh A, Hamzeh K. Ablation of atrial fibrillation using microwave energy-early experience. Asian Cardiovasc Thorac Ann. 2005;13:247-50.

Khargi K, Deneke T, Haardt H, Lemke B, Grewe P, Muller $\mathrm{KM}$, et al. Saline-irrigated, cooled-tip radiofrequency ablation is an effective technique to perform the maze procedure. Ann Thorac Surg. 2001;72:S1090-5.

Prasad SM, Maniar HS, Camillo CJ, Schuessler RB, Boineau JP, Sundt TM 3rd, et al. The Cox maze III procedure for atrial fibrillation: long-term efficacy in patients undergoing lone versus concomitant procedures. J Thorac Cardiovasc Surg. 2003;126: 1822-8.

Risk factors for stroke and efficacy of antithrombotic therapy in atrial fibrillation. Analysis of pooled data from five randomized controlled trials. Arch Intern Med. 1994;154:1449-57.

Schumacher B, Luderitz B. Rate issues in atrial fibrillation: consequences of tachycardia and therapy for rate control. Am J Cardiol. $1998 ; 82: 29 \mathrm{~N}-36 \mathrm{~N}$.

Wolf PA, Abott RD, Kannel WB. Atrial fibrillation as an independent risk factor for stroke: The Framingham Study. Stroke. 1991;22:983-8.

Wolf PA, Mitchel JB, Baker CS, Kannel WB, D'Agostino RB. Impact of atrial fibrillation on mortality stroke, and medical cost. Arch Intern Med. 1998;158:229-34. 